Article

\title{
Fruit Yield, Polyphenols, and Carotenoids in Long Shelf-Life Tomatoes in Response to Drought Stress and Rewatering
}

\author{
Cristina Patanè $^{1, *(\mathbb{C}, \text { Sarah Siah }}{ }^{2}$, Alessandra Pellegrino ${ }^{1}$, Salvatore L. Cosentino ${ }^{1,3}\left(\mathbb{D}\right.$ and Laura Siracusa ${ }^{4}(\mathbb{C}$ \\ 1 CNR-Istituto per la BioEconomia (IBE), Sede Secondaria di Catania, Via P. Gaifami 18, 95126 Catania, Italy; \\ alessandra.pellegrino@cnr.it (A.P.); sl.cosentino@unict.it (S.L.C.) \\ 2 Department of Biology and Plant Ecology, Frères Mentouri University, Constantine 1, Route de Ain El Bey, \\ Constantine 25017, Algeria; sarah.siah@umc.edu.dz \\ 3 Dipartimento di Agricoltura, Alimentazione e Ambiente, Università degli Studi di Catania, via Valdisavoia 5 , \\ 95123 Catania, Italy \\ 4 CNR-Istituto di Chimica Biomolecolare (ICB), Sede Secondaria di Catania, Via P. Gaifami 18, \\ 95126 Catania, Italy; laura.siracusa@icb.cnr.it \\ * Correspondence: cristinamaria.patane@cnr.it; Tel.: +39-095-7338395
}

check for

updates

Citation: Patanè, C.; Siah, S.; Pellegrino, A.; Cosentino, S.L.; Siracusa, L. Fruit Yield, Polyphenols, and Carotenoids in Long Shelf-Life Tomatoes in Response to Drought Stress and Rewatering. Agronomy 2021, 11, 1943. https://doi.org/ 10.3390/agronomy11101943

Academic Editor:

Salvatore Camposeo

Received: 31 August 2021

Accepted: 24 September 2021

Published: 27 September 2021

Publisher's Note: MDPI stays neutral with regard to jurisdictional claims in published maps and institutional affiliations.

Copyright: (c) 2021 by the authors. Licensee MDPI, Basel, Switzerland. This article is an open access article distributed under the terms and conditions of the Creative Commons Attribution (CC BY) license (https:// creativecommons.org/licenses/by/ $4.0 /)$.

\begin{abstract}
The Mediterranean long shelf-life tomato (or long storage tomato) is a plant traditionally cultivated under no irrigation in the Southern regions of Italy, whose fruits have typical high sensory and nutritional quality. However, yield levels are kept low under current cultivation conditions. In this study, the effects of repeated cycles of drying and rehydration on crop productivity and nutritional quality of fruits in terms of polyphenols and carotenoids content were assessed in long shelf-life tomatoes cultivated in a typical semi-arid area of Southern Italy. The three local Sicilian landraces 'Custonaci', 'Salina' and 'Vulcano', and the commercial tomato hybrid 'Faino' (control) were submitted to three irrigation treatments: DRY (no irrigation); IRR (long-season full irrigation); REW (drought/rewatering cycles). Total 450, 4710, and $1849 \mathrm{~m}^{3} \mathrm{ha}^{-1}$, were distributed in DRY, IRR, and REW, respectively. At harvest, fruit yield, polyphenols (as total, flavonoids, and hydroxycinnamoyl quinic acids-HCQA), and carotenoids contents (lycopene and $\beta$-carotene) were measured. All cultivars benefitted from very limited irrigation in REW, raising their productivity (up to $+147 \%$ in 'Vulcano') with respect to that of plants overstressed in DRY. Irrigation water use efficiency in REW was higher than that in IRR. Water shortage in REW led to a polyphenols content of fruits that was slightly lower $\left(171.1 \mu \mathrm{g} \mathrm{g}^{-1}\right)$ than that in DRY, but higher than that in IRR $\left(116.8 \mu \mathrm{g} \mathrm{g}^{-1}\right)$. All local landraces had greater contents $\left(>160 \mu \mathrm{g} \mathrm{g}^{-1}\right)$ than control $\left(113.0 \mu \mathrm{g} \mathrm{g}^{-1}\right)$. Under REW and DRY, the two landraces 'Salina' and 'Vulcano' produced fruits with the same polyphenols and flavonoids contents. Overall, the two water stressed treatments (DRY and REW) did not differ for HCQA content $\left(>66 \mu \mathrm{g} \mathrm{g}^{-1}\right)$, which was significantly higher than that in the irrigated plots $(<50.55$ $\left.\mu \mathrm{g} \mathrm{g}^{-1}\right)$. Lycopene content in DRY and REW exceeded $100 \mu \mathrm{g} \mathrm{g}^{-1}$; among local types, 'Vulcano' exhibited the highest content $\left(106.7 \mu \mathrm{g} \mathrm{g}^{-1}\right)$. The $\beta$-carotene content did not change in 'Custonaci' and 'Salina', whereas in 'Vulcano' it was greater in DRY and REW. Only in 'Faino' water limitation in REW exerted a clear promoting effect on $\beta$-carotene content of fruits. The results of the present study reveal how rewatering after long-lasting drought periods is beneficial to long shelf-life tomatoes in terms of productivity. Appropriate drought cycles in REW may also help the fruits to retain high nutritional levels.
\end{abstract}

Keywords: carotenoids; drought stress; flavonoids; long shelf-life tomato; polyphenols; rewatering; yield

\section{Introduction}

Polyphenols and carotenoids are bioactive compounds that have recently gained great attention by scientists and consumers for their beneficial effects on human health [1]. Tomato is a good source of these two classes of secondary metabolites, and a diet rich in 
this vegetable has been associated with reduced risks of cardiovascular diseases and certain types of cancer [2]. For this reason, there is a growing interest by agronomists towards an increase of the contents of these antioxidants in tomato fruits, also in response to modified agronomic techniques devoted to this goal. Among them, water saving irrigation approaches have been extensively documented as strategies to maximize the accumulation of both polyphenols and carotenoids or to control their losses in tomato fruits [3-6].

Several studies have reported increased levels of antioxidants in vegetables as a result of induced environmental stresses, mostly drought stress [6,7]. Roots' exposure to stress triggers the production of reactive oxygen species, which can cause oxidative damages, and under such stressing conditions, plants tend to increase the levels of antioxidants to minimize damages [8]. However, the application of water saving irrigation strategies in any specific environment requires a preliminary assessment on the risks of plant overstressing, which may adversely affect the final crop productivity [9].

The Mediterranean long shelf-life tomato (or long storage tomato) is a crop traditionally cultivated in the Southern regions of Italy, so-called for the thick skin of the fruits, which delays deterioration and extends shelf-life [10,11]. Several landraces exist, which differ for size and shape of fruits [12]. These tomatoes have typical high sensory and nutritional quality, which makes them greatly appreciated by consumers [10]. In Southern regions of Italy, long shelf-life tomatoes are commercialized in local market, representing an important part of local heritage.

Plants of long shelf-life tomato exhibit considerable tolerance to water stress and are traditionally cultivated under no irrigation after initial plant establishment, being selected for centuries under the severe conditions of the Mediterranean climate during the summer $[13,14]$. However, yield levels in this crop are low since the method of cultivation limits plant productivity overall, and no breeding programs for improved productivity have been carried out so far [13]. Water availability for irrigation is one of the main limiting factor in agricultural activities of semi-arid regions of South Italy, and even sporadic water supplies may induce considerable yield increases in the long shelf-life tomato. Moreover, during summer, plants in these areas may be exposed to repeated drought and rehydration conditions due to climatic changes [15], which somehow may be beneficial to crop productivity, in dry areas of Southern Italy. However, it is also important to assess how even few waterings may affect the nutritional quality of fruits. Indeed, no literature exists on plants response to drought stress induced by the application of repeated drought and rewatering in long shelf-life tomatoes, both in terms of plant productivity and antioxidant levels of fruits.

A renewed agronomic management which improves both fruit yield and nutritional quality may help to enhance the interest towards this crop when it is introduced into the modern cropping systems of the Mediterranean cultivation areas and preserve this valuable resource from genetic erosion. In this study, a water saving irrigation approach, where plants were submitted to drying and rehydration cycles, has been applied to long shelf-life tomatoes to assess the effects of repeated rewaterings after long drought periods on crop productivity and nutritional quality of fruits in terms of polyphenols and carotenoids contents.

\section{Materials and Methods}

\subsection{Open-Field Experiment}

Field experiment was conducted during the summer season of 2017 in a flat site of the Eastern coast of Sicily (South Italy, $10 \mathrm{~m}$ a.s.1., $37^{\circ} 24^{\prime} 35.8^{\prime \prime} \mathrm{N}$ Lat, $15^{\circ} 03^{\prime} 31.7^{\prime \prime} \mathrm{E}$ Long), on a Vertic Xerochrepts soil. The soil characteristics were: clay $28.3 \%$, sand $49.3 \%$, loam $22.4 \%$, organic matter $1.4 \%$, pH 8.6, total $\mathrm{N} \mathrm{1.0 \% ,} \mathrm{available} \mathrm{P}_{2} \mathrm{O}_{5} 5$ ppm, exchangeable $\mathrm{K}_{2} \mathrm{O} 245 \mathrm{ppm}$, bulk density $1.1 \mathrm{~g} \mathrm{~cm}^{-3}$, field capacity $(-0.03 \mathrm{MPa}) 0.27 \mathrm{~g} \mathrm{~g}^{-1}$, wilting point $(-1.5 \mathrm{MPa}) 0.11 \mathrm{~g} \mathrm{~g}^{-1}$. Fallow preceded the cultivation of tomato crop. The seedbed was prepared after the first autumn rains by means of vibro-cultivation followed by a mechanical soil milling at 20-cm soil depth just before transplant. 
The local Sicilian landraces 'Custonaci', 'Salina', and 'Vulcano' of long shelf-life tomato from the germplasm collection at CNR-IBE (Catania, Italy) were used for the experiment and were compared to the commercial 'Faino' Hy. (Syngenta seeds, The Netherland) of mini plum tomato. Plants were transplanted at the four-leaf stage, on April 21, in single plots of $12.0 \mathrm{~m}^{2}(3.0 \mathrm{~m} \times 4.0 \mathrm{~m})$. Plants were spaced $0.75 \mathrm{~m}$ between rows and $0.40 \mathrm{~m}$ within rows, resulting in a plant density of approximately 3.3 plants $\mathrm{m}^{-2}$. Before transplanting, 75,100 , and $100 \mathrm{~kg} \mathrm{ha}^{-1}$ of $\mathrm{N}$ (as ammonium sulphate), $\mathrm{P}_{2} \mathrm{O}_{5}$ (as mineral perphosphate), and $\mathrm{K}_{2} \mathrm{O}$ (as potassium sulphate), respectively, were distributed. Approximately 30 days after transplanting, a further $75 \mathrm{~kg} \mathrm{ha}^{-1}$ of $\mathrm{N}$ (as ammonium nitrate) was supplied as top dressing.

The experiment was arranged in a $3 \times 4$ factorial design with three replicates, where two experimental factors were studied: (i) irrigation (applied to the main plot); (ii) cultivars (applied to subplot). The following three irrigation treatments were applied to the four cultivars of tomato, via a drip-irrigation system: DRY (no irrigation); IRR (long-season full irrigation); REW (post-drought rewaterings). Immediately after transplanting, all plants were irrigated up to field capacity ( $45 \mathrm{~mm}$ of water distributed). To calculate the amount of water to distribute at transplant, soil water content was measured gravimetrically collecting soil samples in three different replicates. Soil samples were then oven-dried at $105^{\circ} \mathrm{C}$ and weighed until constant weight was reached. After that, irrigation in DRY was suspended according to the traditional method of cultivation of long shelf-life tomato [13]. In IRR, irrigation was applied according to the soil-water balance method (Evapotranspiration-ETc $=\mathrm{ET}_{0} \times \mathrm{kc}$ ), restoring the $100 \% \mathrm{ETc} . \mathrm{ET}_{0}$ (reference ET) was measured by means of a class-A evaporation pan, and kc (crop coefficient) was used according to Patanè et al. [16]. The volume of water (V) to supply with irrigation was calculated on the basis of maximum available soil water content (ASWC) in the first $0.40 \mathrm{~m}$ of soil depth, according to Patanè and Saita [17]. Plants were irrigated when the sum of ETc corresponded to $\mathrm{V}(\sim 42 \mathrm{~mm})$ until the fruit ripening stage (mid-July). In REW, plants were submitted to drying and rewatering cycles: after irrigation at transplanting, the soil was left to dry until available soil water was totally used by the crop (i.e., at wilting point), then irrigation was applied again (approximately 8 weeks after transplant) to fulfil the soil capacity at approximately $0.40 \mathrm{~m}$ depth ( $70 \mathrm{~mm}$ of water applied by irrigation) and left drying up again until the next rewatering (after 3 weeks) for a total of two water applications (after that initial). In this way, two long-lasting periods of water stress were imposed to the crop. The total seasonal volume of water distributed by irrigation in DRY, IRR, and REW, was 450,4710 , and $1849 \mathrm{~m}^{3} \mathrm{ha}^{-1}$, respectively.

No chemical herbicides were used for weed control. A hand weeding was performed once only, since the crop covered the soil and weeds could no longer grow.

The following meteorological variables were recorded daily throughout the crop growing season: air temperature, rainfall, class-A pan evaporation, using a data logger (CR10, Campbell Scientific, Logan, UT, USA) located approximately $50 \mathrm{~m}$ from the experimental field. In order to assess the available soil water deficit, during the field experiment from early May until the mid of July, soil water content was measured by means of gypsum blocks (Soilmoisture Equipment Corp., Santa Barbara, CA, USA) located at $0.4 \mathrm{~m}$ soil depth, in all replicates of each irrigation treatment. Measurements were carried out almost always before and after each watering. Thereafter, soil water deficit (SWD) was expressed as percentage of maximum available water according to the following formula:

$$
\mathrm{SWD}=(1-(\mathrm{WC}-\mathrm{WP}) /(\mathrm{FC}-\mathrm{WP})) \times 100
$$

where WC is the soil water content as a percentage of dry soil; FC is the soil water content at field capacity as a percentage of dry soil; and WP is the soil water content at wilting point as a percentage of dry soil.

The crop was hand harvested when the ripe fruits reached $95 \%$ (late July). At harvest, total fruit yield ( $\mathrm{t} \mathrm{ha} \mathrm{a}^{-1}$ ), marketable yield $\left(\mathrm{t} \mathrm{ha}^{-1}\right)$ (considering red and disease-free fresh fruits), yield losses (as \% of fruits unmarketable on total yield), and irrigation water use 
efficiency (IWUE, $\mathrm{kg} \mathrm{m}^{-3}$ ) were calculated, the latter by considering the total amount of water applied by irrigation per each water treatment. Fruits (approx. $2 \mathrm{~kg}$ per cultivar per replicate) from the first two trusses were selected from each plot according to the level of ripeness.

\subsection{Laboratory Analyses}

Fruits sampled at harvest were washed with running water to remove dirt and dried thoroughly with absorbent paper. Then they were analysed for polyphenols (as total, flavonoids, and hydroxycinnamoyl quinic acids-HCQA), and carotenoids (lycopene and $\beta$-carotene).

All analyses were carried out in triplicate.

\subsubsection{Chemicals}

All solvents and reagents used in this study were high purity laboratory products obtained from Carlo Erba (Milano, Italy); HPLC grade water, acetonitrile, and ethyl acetate were purchased from VWR (Milano, Italy). The analytical standards used as references were in the purity range between $90 \%$ and $99 \%$ as declared by the corresponding vendors. Cynarin (1,3-dicaffeoylquinic acid) was provided by Extrasynthese (Lyon, France); chlorogenic acid, rutin, quercetin, and narigenin were obtained from Fluka, whilst all-trans lycopene and $\beta$-carotene were provided by Sigma (Sigma-Aldrich s.r.l., Milano, Italy). A complete list of polyphenols and carotenoids identified in this study and grouped according to their biochemical class is given in Supplementary Material, Table S1.

\subsubsection{Sample Preparation}

Approximately $500 \mathrm{~g}$ of fresh fruits were finely grounded with an electric blender to a homogeneous reddish puree. For the analysis of tomato polyphenols, aliquots $(1 \mathrm{~g})$ of samples were put in $8 \mathrm{~mL}$ amber sample vials and $2 \mathrm{~mL}$ of a hydro-alcoholic solution (80\% methanol in water) was added. Samples were then maintained at room temperature $\left(20{ }^{\circ} \mathrm{C}\right)$ overnight, in the dark, and under vigorous shaking $(350 \mathrm{rpm})$. The resulting heterogeneous yellowish mixtures were then filtered with PTFE filters (15 mm diameter, $0.45 \mu \mathrm{m}$ pore size, Chemtek Analytica, Bologna, Italy) and then further split into two aliquots for qualitative and quantitative analyses. Tomato carotenoids were extracted using the method proposed by Sharma and Le Maguer [18] and adapted by Siracusa et al. [12] When required, the above mentioned analytical samples were stored for shorts periods (one week at the most) at $-20^{\circ} \mathrm{C}$ under nitrogen atmosphere.

\subsubsection{HPLC/DAD Quantitative Analyses}

Quantitative analyses were carried out on a Ultimate3000 "UHPLC focussed" instrument equipped with a binary high pressure pump, a Photodiode Array detector, a Thermostatted Column Compartment, and an Automated Sample Injector (Thermo Scientific, Milano, Italy). Collected data were processed through a Chromeleon Chromatography Information Management System v. 6.80. Chromatographic runs were all performed using a reverse-phase column (Gemini C18, $250 \times 4.6 \mathrm{~mm}, 5 \mu \mathrm{m}$ particle size, Phenomenex, Bologna, Italy) equipped with a guard column (Gemini C18, $4 \times 3.0 \mathrm{~mm}, 5 \mu \mathrm{m}$ particle size, Phenomenex, Italy). The temperature was kept at $25^{\circ} \mathrm{C}$, the flow rate was $1 \mathrm{~mL} / \mathrm{min}$ and the injector volume selected was $20 \mu \mathrm{L}$. Tomato polyphenols and carotenoids were eluted, identified and quantified according to Siracusa et al. [12]. All analyses were carried out in triplicate; results are reported in microgram $(\mu \mathrm{g})$ of compound per gram $(\mathrm{g})$ of vegetable material fresh weight (FW).

\subsubsection{HPLC/DAD/ESI-MS Analyses (Identification of Tomato Polyphenols)}

Variable aliquots $(0.6-0.9 \mathrm{~mL})$ of the above mentioned hydro-alcoholic solutions containing tomato polyphenols were transferred into standard laboratory vials and brought to dryness in vacuo with a rotary evaporator (Heidolph Laborota 400, Deltek srl, Pozzuoli, 
$\mathrm{NA}$, Italy). The resulting yellow residues were then re-dissolved in $250 \mu \mathrm{L}$ of the original $80 \% \mathrm{MeOH}$ solution and submitted to qualitative analyses.

Tomato polar extracts were analysed by HPLC/DAD/ESI-MS using a Waters instrument (Waters Italia S.p.A., Milano, Italy) consisting of a 1525 Binary HPLC Pump, a PDA 996 Photodiode Array Detector (DAD) and a Micromass ZQ Mass Analyser equipped with a ESI Z-spray source. DAD analyses were carried out in the range between 600 and $190 \mathrm{~nm}$, setting the detector at $280 \mathrm{~nm}$ for flavanones (naringenin and its derivatives), at $330 \mathrm{~nm}$ for mono- and di-cinnamoylquinic acids, at $350 \mathrm{~nm}$ for glycosylated flavonoids, and at $370 \mathrm{~nm}$ for quercetin (aglycone). Total ion current (TIC) chromatograms were acquired in negative mode, using a cone voltage of $-25 \mathrm{~V}$ in the mass range between 80 and $1200 \mathrm{~m} / \mathrm{z}$ units. The other parameters used for the acquisition of the TICs were the following: capillary voltage: $2.75 \mathrm{kV}$; source temperature: $150{ }^{\circ} \mathrm{C}$; desolvation temperature: $280^{\circ} \mathrm{C}$; gas flow, L/h: 400 (desolvation) and 210 (cone).

Chromatographic analyses were run using the same conditions (solvents, elution program, column) described in Siracusa et al. [12].

\subsection{Statistical Analyses}

Data of fruit yield, IWUE, polyphenols (as total, flavonoids, and HCQA), and carotenoids (lycopene and $\beta$-carotene) contents were subjected to a split-plot analysis of variance (ANOVA) using CoStat version 6.003 software (CoHort Software, Monterey, CA, USA), considering irrigation and cultivar and their interaction as sources of variation. Means were separated by the Tukey's test at 95\% confidence level.

\section{Results}

\subsection{Meteorological Course}

The meteorological course during the field experiment was that of a typically Mediterranean environment, with hot and dry summer (Figure 1). Maximum temperature measured during the crop growing season ranged from $19.8^{\circ} \mathrm{C}$ (late April) to $41.3{ }^{\circ} \mathrm{C}$ (mid-July), those minimum from $7.1^{\circ} \mathrm{C}$ (late April) to $24.6^{\circ} \mathrm{C}$ (mid-July). Total rainfall during the experiment was very scarce (total $12.2 \mathrm{~mm}$ from late April to late July). Therefore, soil water availability was totally due to irrigation. Maximum daily reference evapotranspiration $\left(\mathrm{ET}_{0}\right)$ (approx. $8 \mathrm{~mm}$ ) during the experiment was recorded in mid-July, according to the highest maximum air temperature.

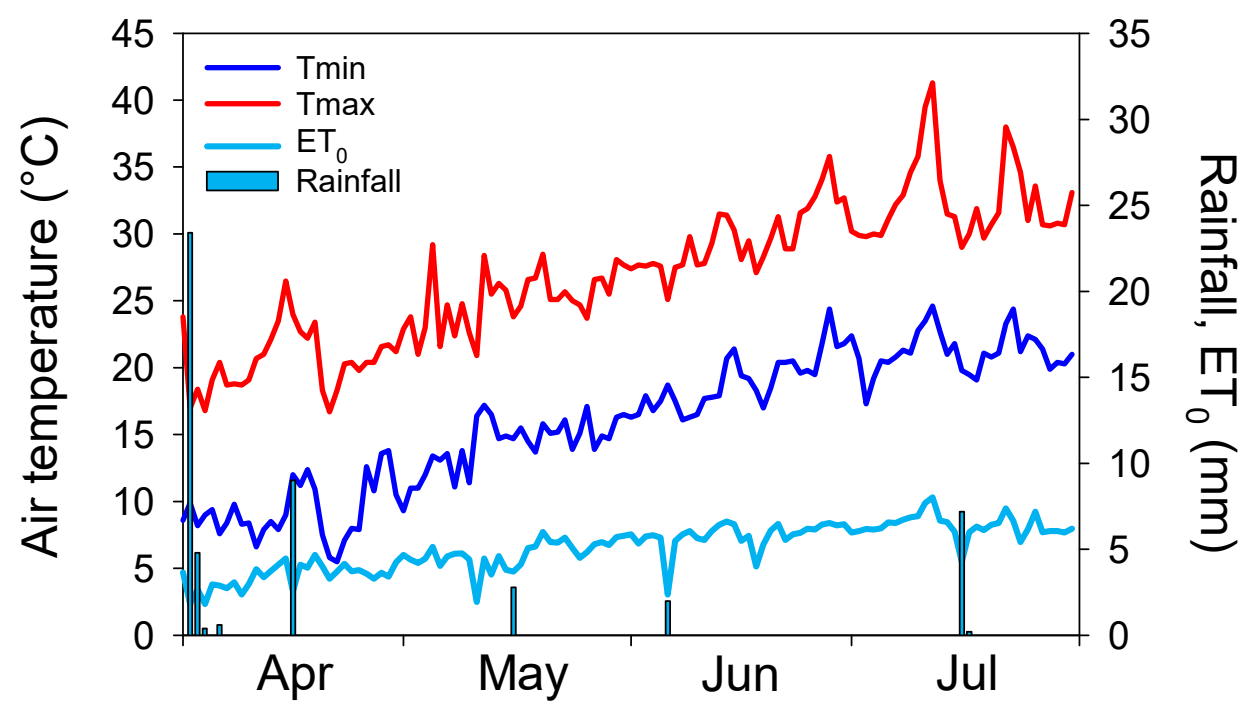

Figure 1. Meteorological course (maximum-Tmax and minimum-Tmin air temperatures, rainfall, reference evapotranspiration-ET $\mathrm{ET}_{0}$ ) recorded during the field experiment. 
The course of soil water deficit as measured throughout the growing season indicates that soil water content in DRY treatment declined just after the cut of irrigation, dropping below the theoretical threshold for irrigation (SWD 66\%) from early June onward (Figure 2). Available soil water content in IRR treatment widely fluctuated, but kept always higher than threshold for irrigation, because the supplied volume of water was indirectly calculated on ETc basis and not on the basis of actual soil water content at the irrigation time. Therefore, under such soil water conditions, tomato plants didn't meet stressful conditions. Under REW, SWD followed the same course as in DRY, up to half-June, then it approached to zero after irrigation, dropping again down to $~ 90 \%$ in mid-July, when a second watering was applied. Just after that, SWD approached zero, to drop below threshold again, up to fruit harvest.

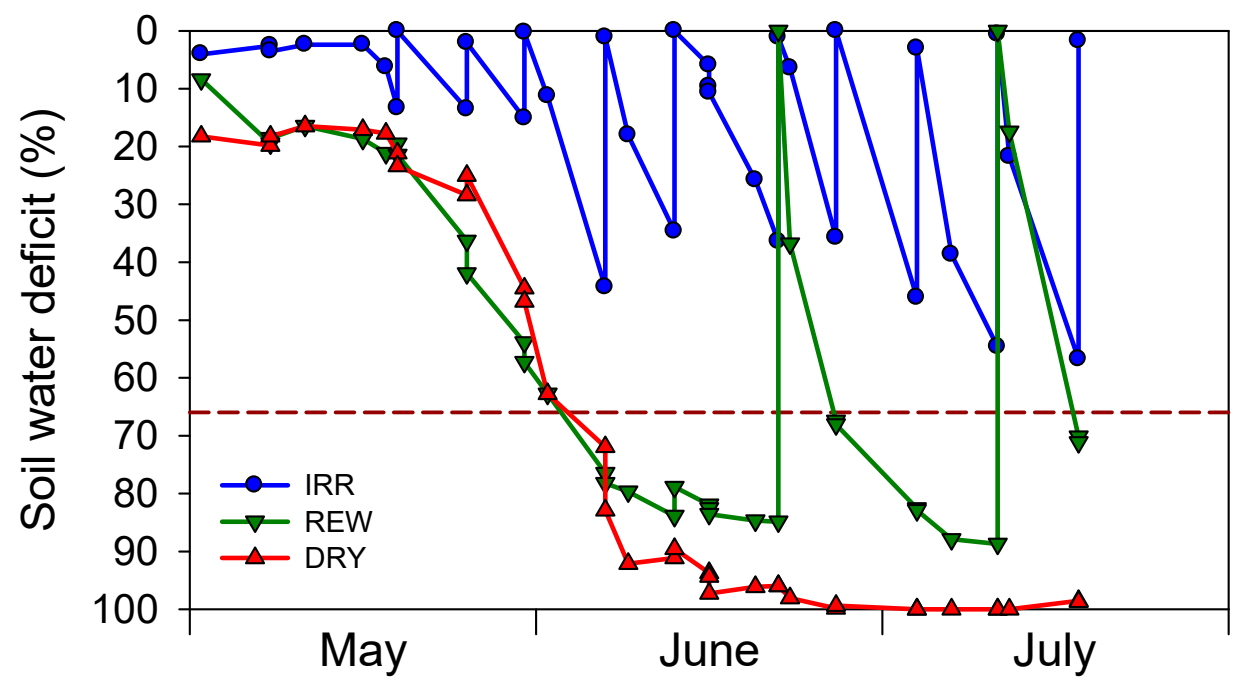

Figure 2. Soil water deficit at a depth of $0.40 \mathrm{~m}$ in each irrigation treatment. Constant horizontal short dash line indicates minimum threshold of available soil water content.

\subsection{Fruit Yield and Irrigation Water Use Efficiency}

Total fruit yield was significantly influenced by the irrigation treatment, cultivar, and their interaction (Table 1).

Table 1. ANOVA results for fruit yield and IWUE in four cultivars of tomato in relation to the irrigation treatments. Degree of freedom (df).

\begin{tabular}{|c|c|c|c|c|c|}
\hline \multirow[t]{2}{*}{ Source } & \multirow[t]{2}{*}{ df } & $\begin{array}{l}\text { Total Yield } \\
\quad\left(\mathrm{t} \mathrm{ha}^{-1}\right)\end{array}$ & $\begin{array}{l}\text { Market. Yield } \\
\quad\left(\mathrm{t} \mathrm{ha}^{-1}\right)\end{array}$ & $\begin{array}{l}\text { Yield Losses } \\
\qquad\left(\mathrm{t} \mathrm{ha}^{-1}\right)\end{array}$ & $\begin{array}{c}\text { IWUE } \\
\left(\mathrm{kg} \mathrm{m}^{-3}\right)\end{array}$ \\
\hline & & \multicolumn{3}{|c|}{$p$} & \\
\hline Irrigation $(I)$ & 2 & $<0.001$ & $<0.001$ & $<0.001$ & $<0.001$ \\
\hline Cultivar (C) & 3 & $<0.001$ & $<0.001$ & $<0.001$ & $<0.001$ \\
\hline$I \times C$ & 6 & $<0.001$ & $<0.001$ & 0.012 & $<0.001$ \\
\hline
\end{tabular}

All cultivars produced significantly less under dry conditions, and their final yield in DRY was reduced on average by the $66 \%$ with respect to that obtained under full irrigation (IRR) (Table 2). Among them, landraces 'Salina' and 'Custonaci' exhibited the highest and the lowest tolerance to severe water deficit, respectively, producing 55\% ('Salina') and 70\% ('Custonaci') less, moving from IRR to DRY conditions $(I \times C, p \leq 0.05)$. All cultivars benefitted from very limited irrigation in REW, raising their productivity (up to $+147 \%$ in 'Vulcano') with respect to that under no irrigation (DRY). Under these experimental conditions, all landraces produced more than $40 \mathrm{t} \mathrm{ha}^{-1}$. 
Table 2. Fruit yield (as total and marketable), yield losses, and IWUE in four cultivars of tomato in relation to the irrigation treatments (IRR: full irrigation; DRY: no irrigation; REW: rewatering). Values are mean \pm standard error $(n=3)$. Values for the main factors followed by the same letter do not statistically differ at $p \leq 0.05$ (Tukey's test). $\operatorname{LSD}_{I \times C}=$ Least significant difference for the interaction 'Irrigation $(I) \times$ Cultivar $(C)$ '.

\begin{tabular}{|c|c|c|c|c|c|c|}
\hline & Treatment & $\begin{array}{l}\text { Total Fruit Yield } \\
\quad\left(t h^{-1}\right)\end{array}$ & $\begin{array}{l}\text { Market. Yield } \\
\quad\left(\mathrm{t} \mathrm{ha} \mathbf{a}^{-1}\right)\end{array}$ & $\begin{array}{l}\text { Yield Losses } \\
\quad\left(t h^{-1}\right)\end{array}$ & $\begin{array}{l}\text { Yield Losses } \\
\text { (\%) }\end{array}$ & $\begin{array}{c}\text { IWUE } \\
\left(\mathrm{kg} \mathrm{m}^{-3}\right)\end{array}$ \\
\hline \multirow[t]{3}{*}{ Custonaci } & IRR & $81.57 \pm 1.6$ & $74.53 \pm 0.9$ & $7.03 \pm 0.3$ & $8.46 \pm 0.6$ & $17.32 \pm 1.2$ \\
\hline & DRY & $24.22 \pm 2.0$ & $22.31 \pm 1.8$ & $1.91 \pm 0.3$ & $7.77 \pm 0.4$ & $53.82 \pm 4.5$ \\
\hline & REW & $40.96 \pm 0.8$ & $35.90 \pm 0.2$ & $5.05 \pm 0.6$ & $12.27 \pm 1.2$ & $22.15 \pm 0.4$ \\
\hline \multirow[t]{3}{*}{ Salina } & IRR & $68.39 \pm 0.6$ & $60.18 \pm 2.0$ & $8.21 \pm 1.5$ & $12.07 \pm 2.2$ & $14.52 \pm 0.1$ \\
\hline & DRY & $30.54 \pm 1.1$ & $27.07 \pm 0.8$ & $3.46 \pm 0.2$ & $11.31 \pm 0.3$ & $67.86 \pm 2.4$ \\
\hline & REW & $46.68 \pm 1.9$ & $40.70 \pm 1.9$ & $5.99 \pm 0.01$ & $12.90 \pm 0.6$ & $23.25 \pm 1.0$ \\
\hline \multirow[t]{3}{*}{ Vulcano } & IRR & $60.65 \pm 3.6$ & $51.54 \pm 3.8$ & $9.11 \pm 0.2$ & $15.25 \pm 1.3$ & $12.88 \pm 0.8$ \\
\hline & DRY & $18.65 \pm 2.1$ & $17.14 \pm 2.2$ & $1.52 \pm 0.2$ & $8.74 \pm 1.8$ & $41.45 \pm 4.6$ \\
\hline & REW & $46.04 \pm 9.6$ & $40.45 \pm 8.3$ & $5.60 \pm 1.4$ & $11.85 \pm 0.5$ & $24.90 \pm 5.2$ \\
\hline \multirow[t]{11}{*}{ Faino Hy } & IRR & $114.87 \pm 3.4$ & $91.46 \pm 2.8$ & $23.41 \pm 6.2$ & $19.95 \pm 4.8$ & $24.39 \pm 0.7$ \\
\hline & DRY & $37.72 \pm 3.5$ & $33.54 \pm 3.0$ & $4.18 \pm 0.5$ & $11.01 \pm 0.3$ & $83.83 \pm 7.9$ \\
\hline & REW & $56.67 \pm 3.9$ & $47.80 \pm 1.8$ & $8.87 \pm 2.0$ & $15.13 \pm 2.5$ & $30.65 \pm 2.1$ \\
\hline & IRR & $81.37 \mathrm{a}$ & $69.43 \mathrm{a}$ & $11.94 \mathrm{a}$ & 11.93 & $17.28 \mathrm{c}$ \\
\hline & DRY & $27.78 \mathrm{c}$ & $25.01 \mathrm{c}$ & $2.77 \mathrm{c}$ & 9.97 & $61.74 \mathrm{a}$ \\
\hline & REW & $47.59 \mathrm{~b}$ & $41.21 \mathrm{~b}$ & $6.38 \mathrm{~b}$ & 13.41 & $25.74 \mathrm{~b}$ \\
\hline & Custonaci & $48.92 \mathrm{~b}$ & $44.25 \mathrm{~b}$ & $4.66 \mathrm{~b}$ & 9.50 & $31.10 \mathrm{bc}$ \\
\hline & Salina & $48.54 \mathrm{~b}$ & $42.65 \mathrm{~b}$ & $5.89 \mathrm{~b}$ & 12.13 & $35.87 \mathrm{~b}$ \\
\hline & Vulcano & $41.78 \mathrm{c}$ & $36.37 \mathrm{c}$ & $5.41 \mathrm{~b}$ & 12.95 & $26.41 \mathrm{c}$ \\
\hline & Faino Hy & $69.75 \mathrm{a}$ & $57.60 \mathrm{a}$ & $12.15 \mathrm{a}$ & 17.42 & $46.29 \mathrm{a}$ \\
\hline & $\mathrm{LSD}_{I \times C}$ & 10.62 & 9.24 & 5.80 & & 10.22 \\
\hline
\end{tabular}

However, yield losses widely differed with the irrigation treatment, significantly affecting the marketable yield. Yield losses were minimized ( $<10 \%$, on average of cultivars) under no irrigation, and were more conspicuous (approx. 20\%) in 'Faino' well-watered $(I \times C, p \leq 0.05)$. Water limitation in REW caused an increased loss of product over the DRY treatment; nonetheless, marketable yield maintained levels that in all cases were significantly higher than those of the corresponding unirrigated plots.

IWUE was maximized in the control 'Faino'. Overall, the irrigation water was used in a more efficient way (higher IWUE) under restricted soil water availability in REW than under no water limitations in IRR. Differently than in DRY and IRR, in REW no differences were ascertained among cultivars for IWUE $\left(>22 \mathrm{~kg} \mathrm{~m}^{-3}\right)(I \times C, p<0.001)$, although local tomato landraces have never been included in breeding programs for IWUE improvement.

\subsection{Total Polyphenols, Flavonoids, and Hydroxycinnamoyl Quinic Acids (HCQA) Content}

Polyphenols content significantly varied with irrigation and cultivar $(p<0.001)$ (Table 3). It was maximized in fruits of DRY plots (192.5 $\mu \mathrm{g} \mathrm{g}^{-1}$ ) (Figure 3). Water shortage in REW led to a polyphenols content of fruits that was slightly lower $\left(171.1 \mu \mathrm{g} \mathrm{g}^{-1}\right)$ than that in DRY, but higher than that in IRR $\left(116.8 \mu \mathrm{g} \mathrm{g}^{-1}\right)$. All local landraces had greater contents in polyphenols $\left(>160 \mu \mathrm{g} \mathrm{g}^{-1}\right)$ than control 'Faino' $\left(113.0 \mu \mathrm{g} \mathrm{g}^{-1}\right)$. However, tomato cultivars differently responded to the irrigation treatment for this trait $(I \times C, p \leq 0.01)$. In particular, in the two landraces 'Salina' and 'Vulcano', fruits produced under REW and DRY treatments exhibited the same polyphenols content.

The content of flavonoids (mostly rutin and naringerin, see Table S1) in tomato fruits was significantly influenced by both the experimental factors $(p<0.001)$ and their interaction $(p<0.01)$. This trait was adversely affected by high rates of irrigation in IRR $\left(66.2 \mu \mathrm{g} \mathrm{g}^{-1}\right.$ ) (Figure 4). Conversely, severe water stress conditions in REW and, more, in DRY, led to high levels of flavonoids ( $>100 \mu \mathrm{g} \mathrm{g}{ }^{-1}$ in both) in tomato fruits. Among cultivars, the highest content corresponded to 'Vulcano' $\left(<128 \mu \mathrm{g} \mathrm{g}^{-1}\right)$ and the lowest to the control 'Faino' ( $\left.82.3 \mu \mathrm{g} \mathrm{g}^{-1}\right)$. The two experimental factors significantly interacted on this 
trait, and as for polyphenols, in long-shelf life tomato 'Salina' and 'Vulcano', flavonoids in DRY and REW did not differ for this trait.

Table 3. ANOVA results for polyphenols, flavonoids, and HCQA content, in four cultivars of tomato in relation to the irrigation treatments. Degree of freedom (df).

\begin{tabular}{|c|c|c|c|c|}
\hline \multirow[t]{2}{*}{ Source } & \multirow[t]{2}{*}{$\mathrm{df}$} & $\begin{array}{l}\text { Polyphenols } \\
\left(\mu \mathrm{g} \mathrm{g}^{-1}\right)\end{array}$ & $\begin{array}{c}\text { Flavonoids } \\
\left(\mu \mathrm{g} \mathrm{g}^{-1}\right)\end{array}$ & $\begin{array}{c}\text { HCQA } \\
\left(\mu \mathrm{g} \mathrm{g}^{-1}\right)\end{array}$ \\
\hline & & \multicolumn{3}{|c|}{$p$} \\
\hline Irrigation $(I)$ & 2 & $<0.001$ & $<0.001$ & $<0.001$ \\
\hline Cultivar (C) & 3 & $<0.001$ & $<0.001$ & $<0.001$ \\
\hline$I \times C$ & 6 & 0.0011 & 0.0054 & 0.0033 \\
\hline
\end{tabular}

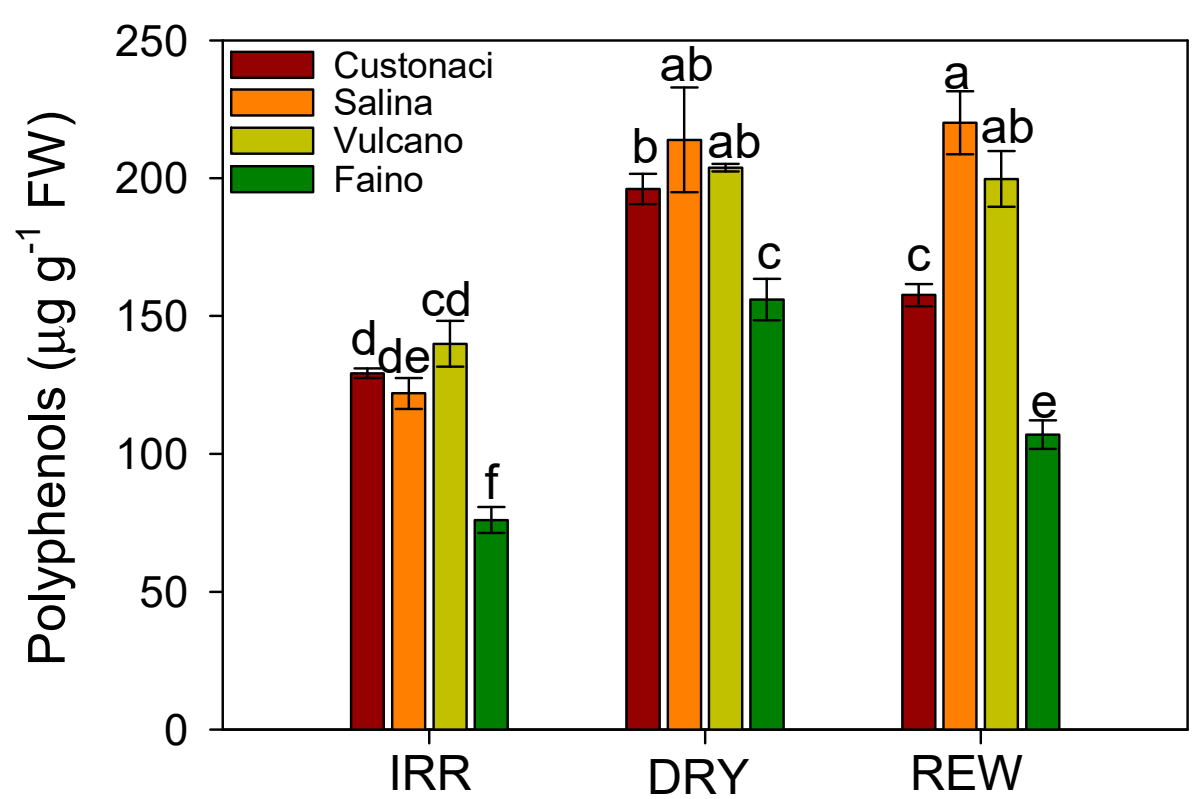

Figure 3. Polyphenols content in fruits of four cultivars of tomato in response to irrigation (IRR: full irrigation; DRY: no irrigation; REW: rewatering). Bars are mean value \pm standard error $(n=3)$. Different letters among cultivars across irrigation treatments indicate significance at $p \leq 0.05$ by Tukey's test.

The content of hydroxycinnamoyl quinic acids (HCQA), mostly represented by caffeic acid hexadise and chlorogenic acid, exhibited a pattern different than that reported for total polyphenols and flavonoids, with wider differences among cultivars and irrigation treatments $(p<0.001)$. Fruits of local landrace from Salina Island were the richest in HCQA $\left(85.33 \mu \mathrm{g} \mathrm{g}^{-1}\right)$, those of the control 'Faino' were the poorest $\left(35.83 \mu \mathrm{g} \mathrm{g}^{-1}\right)$ (Figure 5). The two water stressed treatments (DRY and REW) did not differ for HCQA content $\left(>66 \mu \mathrm{g} \mathrm{g}^{-1}\right)$, which was significantly higher than that in the irrigated plots $\left(<50.55 \mu \mathrm{g} \mathrm{g}^{-1}\right)$. However, a significant interactive effect of the two factors was observed in the ANOVA. In long shelf-life tomato 'Custonaci', HCQA content did not change with the irrigation treatment, whereas a clear depressive effect of irrigation was evidenced in 'Salina'. The HCQA content benefitted from severe water deficit conditions in DRY but not in REW, in fruits of 'Vulcano'. Irrigation to very stressed plants in REW resulted in enhanced amount of HCQA in fruits of 'Faino', even higher than that in DRY plots. 


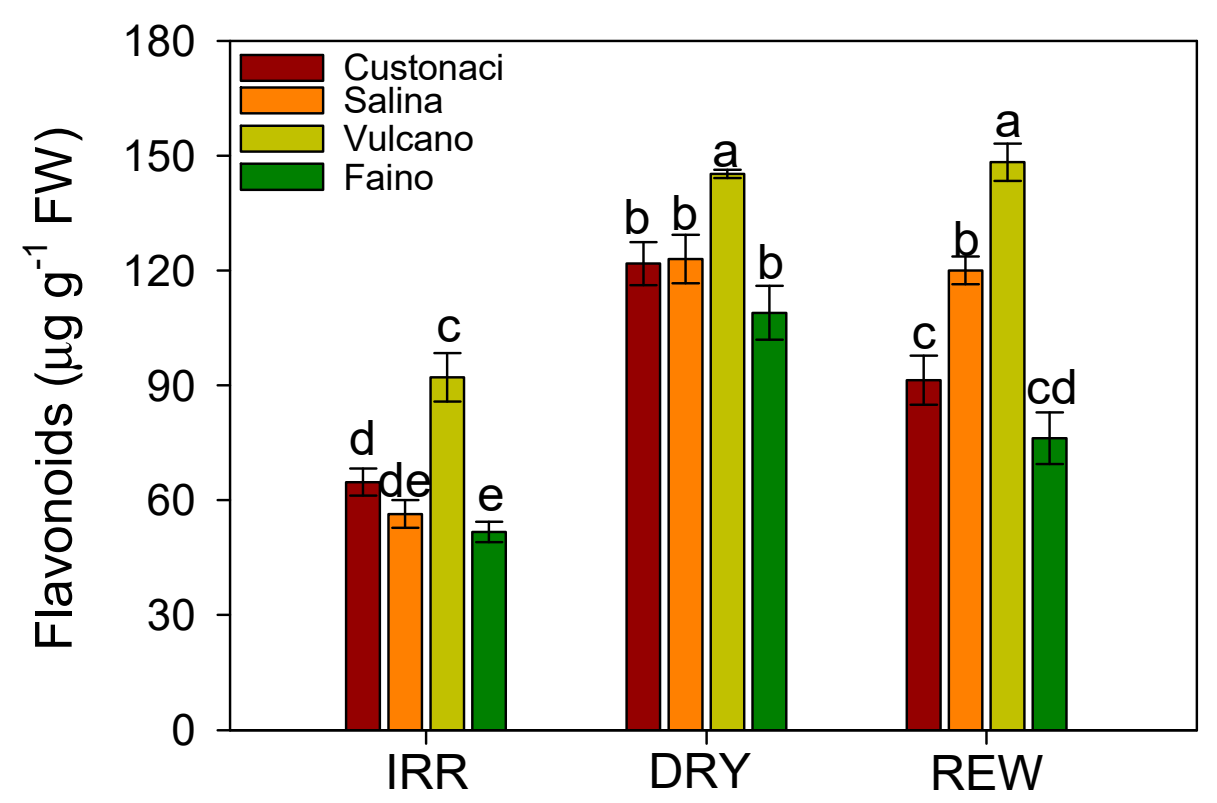

Figure 4. Flavonoids content in fruits of four cultivars of tomato in response to irrigation (IRR: full irrigation; DRY: no irrigation; REW: rewatering). Bars are mean value \pm standard error $(n=3)$. Different letters among cultivars across irrigation treatments indicate significance at $p \leq 0.05$ by Tukey's test.

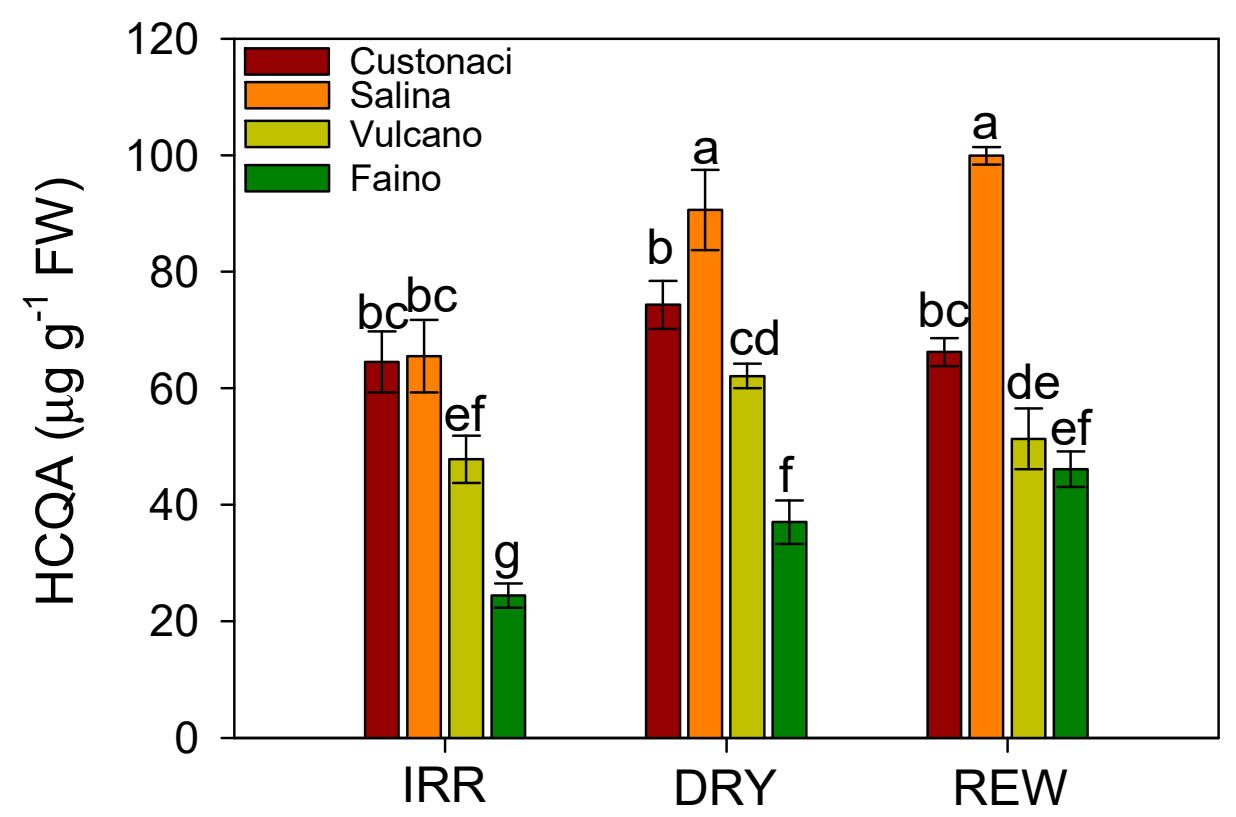

Figure 5. HCQA content in fruits of four cultivars of tomato in response to irrigation (IRR: full irrigation; DRY: no irrigation; REW: rewatering). Bars are mean value \pm standard error $(n=3)$. Different letters among cultivars across irrigation treatments indicate significance at $p \leq 0.05$ by Tukey's test.

\subsection{Carotenoids Content}

Regarding carotenoids, only lycopene and $\beta$-carotene content were considered for this study (see Table S1). The amount of lycopene was influenced by both the experimental factors $(p<0.001)$ but not their interaction $(p>0.05)$ (Table 4$)$. Frequent irrigation in IRR caused significant reduction in lycopene contents (on average $82.3 \mathrm{mg} \mathrm{g}^{-1}$ ). Fruits from plants unirrigated (in DRY) or rewatered (in REW) had a lycopene content that exceeded $100 \mu \mathrm{g} \mathrm{g}^{-1}$. Among local types, 'Vulcano' exhibited the highest content $\left(106.7 \mu \mathrm{g} \mathrm{g}^{-1}\right)$, that 
did not differ from those of 'Custonaci $\left(102.9 \mu \mathrm{g} \mathrm{g}^{-1}\right)$ and the control 'Faino' $\left(103.1 \mu^{-1} \mathrm{~g} \mathrm{~g}^{-1}\right)$ (Figure 6). Overall, fruits of 'Salina' had the lowest lycopene content $\left(79.1 \mu \mathrm{g} \mathrm{g}^{-1}\right)$.

Table 4. ANOVA results for lycopene and $\beta$-carotene content in four cultivars of tomato in relation to the irrigation treatments. Degree of freedom (df); ns (not significant).

\begin{tabular}{cccc}
\hline Source & df & $\begin{array}{c}\text { Lycopene } \\
\left(\mu \mathbf{g ~ g}^{-\mathbf{1})}\right.\end{array}$ & $\begin{array}{c}\beta \text {-carotene } \\
\left(\mu \mathbf{g ~ g}^{-\mathbf{1})}\right.\end{array}$ \\
\cline { 3 - 4 } & & & $\boldsymbol{p}$ \\
\hline Irrigation $(I)$ & 2 & $<0.001$ & $<0.001$ \\
Cultivar $(C)$ & 3 & $<0.001$ & 0.0073 \\
$I \times C$ & 6 & $0.1522^{\mathrm{ns}}$ & 0.0177 \\
\hline
\end{tabular}
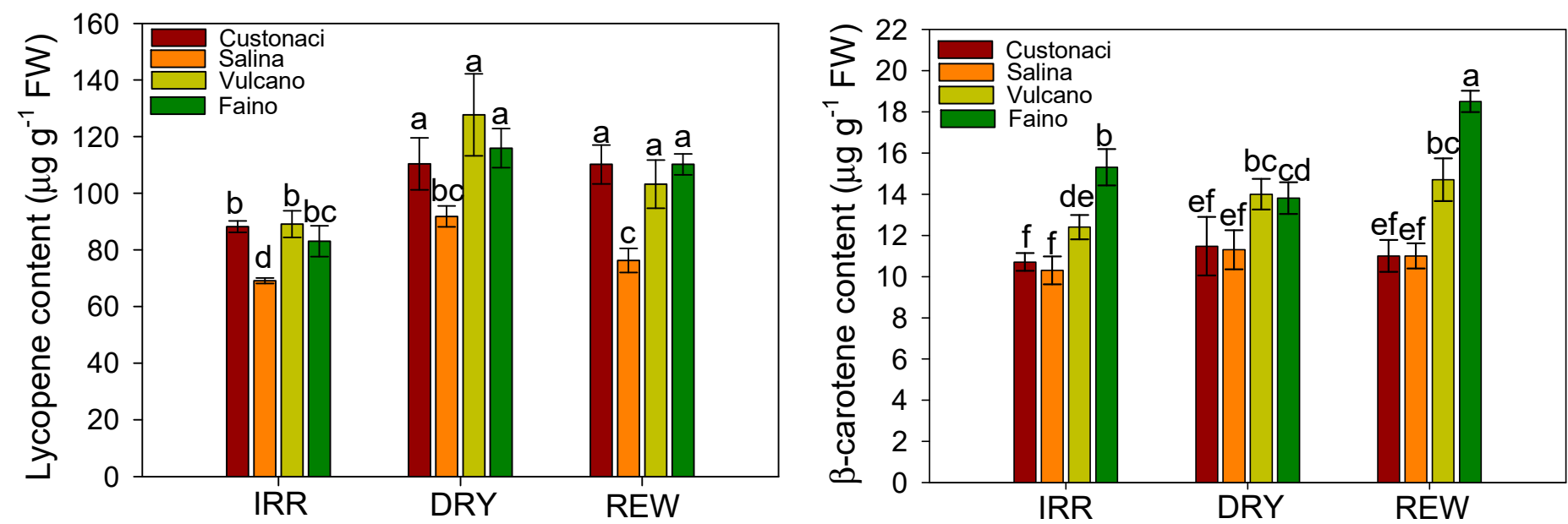

Figure 6. Lycopene (left) and $\beta$-carotene (right) content in fruits of four cultivars of tomato in response to irrigation (IRR: full irrigation; DRY: no irrigation; REW: rewatering). Bars are mean value \pm standard error $(n=3)$. Different letters among cultivars across irrigation treatments indicate significance at $p \leq 0.05$ by Tukey's test.

A different pattern was exhibited by cultivars for $\beta$-carotene content in response to the irrigation treatment $(I \times C, p \leq 0.05)$. 'Custonaci' and 'Salina' did not respond to the irrigation in IRR and REW, maintaining the same content (respectively 10.7 and $11.0 \mu^{-1} \mathrm{~g} \mathrm{~g}^{-1}$, in 'Custonaci', 10.3 and 11.0, $\mu \mathrm{g} \mathrm{g}^{-1}$, in 'Salina') of the DRY control (11.5 $\mu \mathrm{g} \mathrm{g}^{-1}$, in 'Custonaci', $11.3 \mu \mathrm{g} \mathrm{g}^{-1}$, in 'Salina). This did not occur in 'Vulcano', where the slight rise in $\beta$-carotene content measured in fruits of DRY and REW treatments over those of IRR was significant at ANOVA. The control 'Faino' was the only tomato where water limitation in REW exerted a clear promoting effect of on $\beta$-carotene content of fruits.

\subsection{Relationships of Fruit Yield vs. Polyphenols and Carotenoids}

Negative relationships were described between fruit yield vs. polyphenols, flavonoids, and HCQA content in tomato fruits (Figure 7), which indicate that these secondary metabolites tend to decrease as fruit yield increases. However, the relationship was significant for polyphenols (as total) and flavonoids ( $p \leq 0.01)$, but not for HCQA content $(p>0.05)$.

Fruit yield negatively correlated also with lycopene content of tomato fruits $(p<0.05)$ which reveals that, as observed for polyphenols, this carotenoid accumulates slightly but significantly less when fruit yield arises. However, no significant relationship was described for fruit yield vs. $\beta$-carotene $(p>0.05)$. 


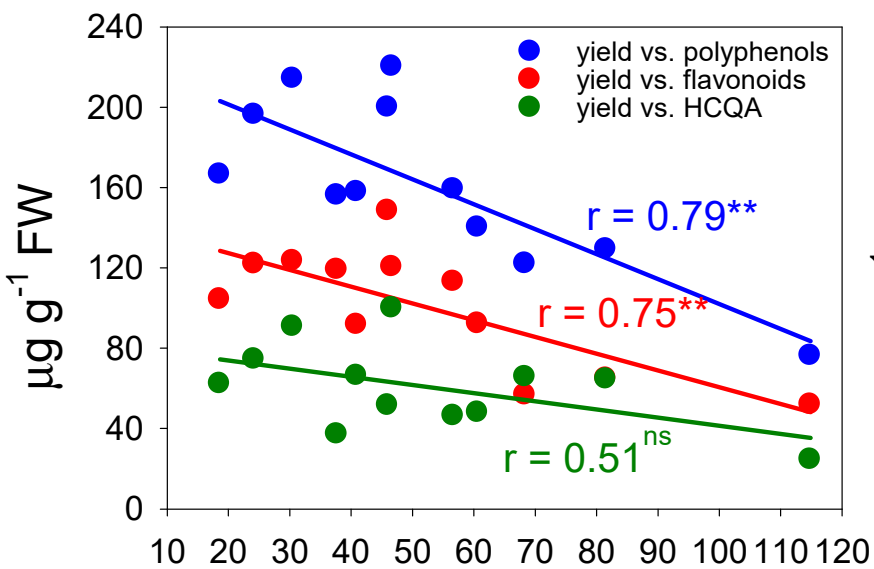

Fruit yield $\left(\mathrm{t} \mathrm{ha}^{-1}\right)$

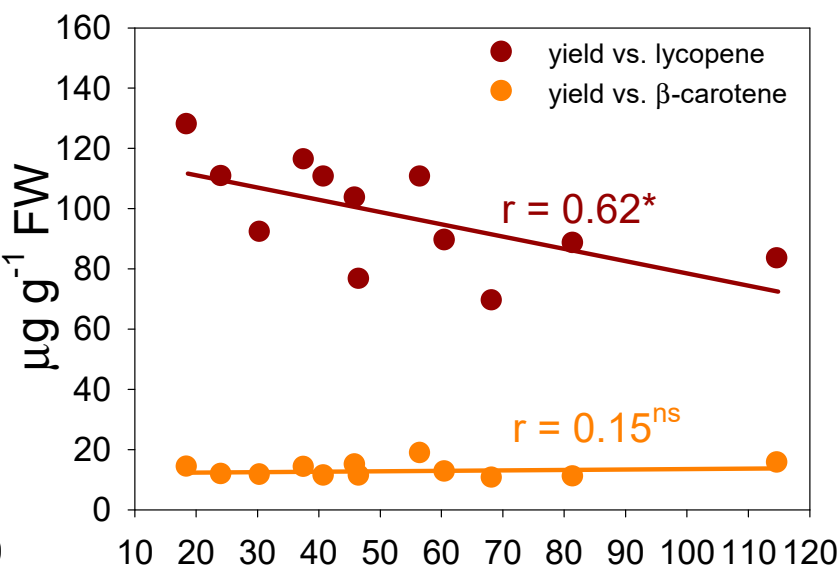

Fruit yield (t ha-1)

Figure 7. Relationships of fruit yield vs. polyphenols (total, flavonoids, HCQA, on the left) and carotenoids (lycopene and $\beta$-carotene, on the right) in tomato. Values of correlation coefficient $(r)$ and significance $\left({ }^{*}, * *\right.$, significant at $p \leq 0.05$ and 0.01 , respectively; ns, not significant) are reported.

\section{Discussion}

In this study, the promoting effect of severe drought conditions on fruit yield and polyphenols and carotenoids accumulation in fruits was examined in three landraces of long shelf-life tomatoes in a semi-arid environment, as compared with a commercial variety of mini plum tomato. The water stress conditions were imposed via no irrigation following plant establishment (DRY treatment), or post-drought rewaterings (REW treatment). All cultivars produced significantly less under severe soil water deficit conditions and final yield in unirrigated plants was reduced, on average, by $66 \%$ with respect to that of fully irrigated plants (IRR). However, local landraces of tomato are traditionally cultivated under no irrigation [13], therefore, the results should be interpreted in a different perspective, assessing their behavior when irrigated. With this in mind, all landraces responded positively to full irrigation, considerably increasing their productivity, up to a $+237 \%$ recorded in 'Custonaci', which was even higher than that occurred in the control 'Faino' (+201\% yield increase). Among local landraces, that from the Salina Island was less responsive to irrigation $(+124 \%$ yield increase, compared to over $+200 \%$ measured in the other cultivars, including the mini plum tomato). Our results indicate that plant productivity response to irrigation in long shelf-life tomatoes is genotypic-specific, as also revealed by the different irrigation water use efficiency (IWUE) corresponding to tomato cultivars. A large difference in fruit yield was also reported in literature between two landraces of long shelf-life tomatoes, cultivated under full irrigation and rainfed conditions [19], which suggests the feasibility to screen within the genetic resources and select for individual genotypes with high yield potential under restricted soil water availability.

All tomato genotypes exhibited a high recovery potential after drought. Very limited water applications after long-term severe drought (at a soil water content close to wilting point) alleviated the water stress, promoting plant productivity. This enhancing effect was more evident in local landraces, whose yield in REW was the 53-69\% higher than that of plants unirrigated (against a $+33 \%$ in 'Faino'). This high yield responsiveness to even a few irrigations, besides the overall low yield levels in local landraces, may be supported by the fact that, differently than commercial cultivars (as the control 'Faino Hy' of miniplum), they have never been bred for high yield [20].

Combined alternate wetting and drying cycles also reduced the yield losses and enhanced the efficiency in water used over the fully irrigated treatment, with economic and environmental benefits in terms of water saving. Similar beneficial effects of reduced water supply on WUE has been extensively reported in literature for tomato $[16,17,21]$. However, if a large literature exists about the effects of rewatering on plant physiology in 
many plants [22-24], including tomato [25,26], no information is available on its effects upon the nutritional aspects of the product.

In this study, polyphenols content in tomato was maximized under long-lasting drought conditions in DRY. Repeated cycles of dehydration and rehydration in REW, besides promoting fruit yield, contributed to maintain high levels of polyphenols in fruits, whilst high rates of irrigation adversely affected the levels of these metabolites, as well as those of flavonoids. In general, the application of water stress has been reported to trigger the synthesis of antioxidant compounds including polyphenols, in vegetables, and the imposition of water stress during cultivation has been proposed as a valuable tool for producing high quality vegetables $[19,27-30]$. A wide literature on tomato supports the results of the present study $[4,5,10]$. Polyphenols in long shelf-life tomatoes were much higher than those in the control 'Faino', even under well-watered conditions. Siracusa et al. [12] reported significantly greater amounts of polyphenols (up to 10-fold higher) in some local landraces of long shelf-life tomato as compared with a commercial cultivar of processing tomato. Polyphenols in fruits of local landraces were less affected by changes in soil water conditions (down to $-16 \%$ less polyphenols in IRR with respect to DRY in 'Vulcano', as compared with $-51 \%$ of 'Faino'), indicating an overall minor response to irrigation.

Flavonoids are the main polyphenols in tomatoes [31]. As the other phenolic compounds, they exert a protection role from oxidative damages in plants exposed to environmental stress [32]. Flavonoids have been reported to accumulate to greater extent in drought-stressed plants [28], including tomato [4]. Similar clear crop response to irrigation were observed in our experiment for flavonoids, whose content was halved in non-stressed plants with respect to that of unirrigated plants. Repeated rewaterings led to a slight $(\sim 14 \%)$ or null decrease of flavonoids with respect to those of plants under DRY treatment, resulting anyway in valuable final amounts in tomato fruits. Overall, flavonoids in local landraces were greater than those in the control 'Faino', especially under full or limited irrigation, and much greater than those reported in literature for small tomato fruits under no irrigation (up to $72.5 \mu \mathrm{g} \mathrm{g}^{-1}$ ) [4], confirming the high nutritional value of these landraces of long shelf-life tomato.

These tomatoes also provided greater hydroxycinnamoyl quinic acids (HCQA) contents than commercial cultivar, regardless of the irrigation treatment. Siracusa et al. [12], working on a collection of long shelf-life tomatoes originating from the Southern regions of Italy, observed how HCQA were more abundant in local landraces than in commercial varieties, and that some HCQA identified in local landraces in high amounts (e.g., diCQA2 and diCQA3, dicaffeoylquinic acids isomers, see Table S1), were minor in commercial tomatoes. Based in their results, the authors proposed the use of these secondary metabolites as biomarkers for the traceability of the product in long shelf-life tomatoes.

In this study, lycopene content ranged from 70 to $128 \mu \mathrm{g} \mathrm{g}^{-1}$, those of $\beta$-carotene from 10 to $19 \mu \mathrm{g} \mathrm{g}^{-1}$. These results confirm the high carotenoids content typical of small tomatoes, which is to ascribed to their thick skin [10] where carotenoids are mostly located [12]. Carotenoids ( $\beta$-carotene to less extent) were overall enhanced in plants subjected to longterm drought or rehydrated during growing season. Although the results on the effects of soil moisture on lycopene and $\beta$-carotene in tomato fruits are still controversial $[3,33]$, some literature indicates that they accumulate in fruits in higher amounts under water deficiency $[6,21]$. The high lycopene and $\beta$-carotene contents measured under REW in the present study confirm these findings. To this regard, a water stress management through the application of water-saving irrigation strategies is proposed as a tool to promote the nutritional properties of tomato in terms of secondary metabolites [34].

\section{Conclusions}

The results of the present study reveal how rewatering after long-lasting drought periods is beneficial to long shelf-life tomatoes. The ability of their plants to recover from drought stress after rewatering was highlighted by a clear rising of yield over plants overstressed under no water supply. Moreover, less yield losses were measured under 
rewatering, with respect to those occurred under unrestricted soil water conditions, and an improvement of irrigation water use efficiency was obtained. This is an important goal in long shelf-life cultivation, whose main limit is represented by the low productivity levels, but where even very limited water supplies (as those in rewatering) may contribute to make this crop more profitable.

The results also revealed that the nutritional traits of the product in long shelf-life tomato are maximized under no irrigation, which is the traditional method of cultivation of this species. However, appropriate drought cycles in REW may help the fruits to retain high quality levels. In fact, high antioxidant contents resulted from severe water stress under no water supply or drought/rewatering cycles, especially in terms of polyphenols. This is another important aspect in the cultivation of tomato, where healthy and high quality fruits are increasingly required. Within carotenoids, $\beta$-carotene was less influenced by soil water conditions. In this sense, polyphenols, more than carotenoids, may be used as valuable indicators of drought tolerance and may be applied in the development of cultivars better adapt to water stressing environments. In this regard, more stable polyphenols content in 'Vulcano' of long shelf-life tomato denotes greater tolerance to water stress.

Drought/rewatering cycles may somehow reflect the impact of sporadic extreme rainy events which may occur during the tomato growth period in the summer, and that are expected to occur with greater frequency under changing climatic conditions, even in arid and semi-arid areas. These results highlight how long shelf-life tomatoes can cope with adverse climatic conditions.

Supplementary Materials: The following are available online at https:/ /www.mdpi.com/article/10 .3390 /agronomy11101943/s1, Table S1, List of the chemical markers identified in tomato samples object of this study. For peak diagnostics, see Siracusa et al. [12]. HCQA = HydroxyCinnamoyl Quinic Acids.

Author Contributions: Conceptualization, C.P. and S.L.C. Data curation, C.P., S.S. and L.S. Formal analysis, C.P., A.P. and S.S. Investigation, C.P., A.P. and S.S. Methodology, C.P., L.S. and S.L.C. Software, C.P. and S.L.C. Validation, C.P. Writing-original draft, C.P. Writing-review and editing, S.L.C. All authors have read and agreed to the published version of the manuscript.

Funding: This research received no external funding.

Institutional Review Board Statement: Not applicable.

Informed Consent Statement: Not applicable.

Data Availability Statement: Not applicable.

Acknowledgments: Authors are grateful to Giancarlo Patanè, University of Catania, for his technical assistance in field.

Conflicts of Interest: The authors declare no conflict of interest.

\section{References}

1. Martí, R.; Roselló, S.; Cebolla-Cornejo, J. Tomato as a source of carotenoids and polyphenols targeted to cancer prevention. Cancers 2016, 8, 58. [CrossRef]

2. Canene-Adams, K.; Campbell, J.K.; Zaripheh, S.; Jeffery, E.H.; Erdman, J.W. The tomato as a functional food. J. Nutr. 2005, 134, 1226-1230. [CrossRef]

3. Dumas, Y.; Dadomo, M.; Di Lucca, G.; Grolier, P. Effects of environmental factors and agricultural techniques on antioxidant content of tomatoes. J. Sci. Food Agric. 2003, 83, 369-382. [CrossRef]

4. Pernice, R.; Parisi, M.; Giordano, I.; Pentangelo, A.; Graziani, G.; Gallo, M.; Fogliano, V.; Ritieni, A. Antioxidants profile of small tomato fruits: Effect of irrigation and industrial process. Sci. Hortic. 2010, 126, 156-163. [CrossRef]

5. Barbagallo, R.N.; Di Silvestro, I.; Patanè, C. Yield, physicochemical traits, antioxidant pattern, polyphenol oxidase activity and total visual quality of field-grown processing tomato cv. Brigade as affected by water stress in Mediterranean climate. J. Sci. Food Agric. 2013, 93, 1449-1457. [CrossRef] [PubMed]

6. Klunklin, W.; Savage, G. Effect on quality characteristics of tomatoes grown under well-watered and drought stress conditions. Foods 2017, 6, 56. [CrossRef] [PubMed] 
7. Oh, M.M.; Carey, E.E.; Rajashekar, C.B. Environmental stresses induce health-promoting phytochemicals in lettuce. Plant Physiol. Biochem. 2009, 47, 578-583. [CrossRef]

8. Atkinson, N.J.; Dew, T.P.; Orfila, C.; Urwin, P.E. Influence of combined biotic and abiotic stress on nutritional quality parameters in tomato (Solanum lycopersicum). J. Agric. Food Chem. 2011, 59, 9673-9682. [CrossRef]

9. Hidaka, K.; Yasutake, D.; Kitano, M.; Takahashi, T.; Sago, Y.; Ishikawa, K.; Kawano, T. Production of high quality vegetables by applying low temperature stress to roots. Acta Hortic. 2008, 801, 1431-1436. [CrossRef]

10. Patanè, C.; Pellegrino, A.; Saita, A.; Siracusa, L.; Ruberto, G.; Barbagallo, R. Mediterranean long storage tomato as a source of novel products for the agrifood industry: Nutritional and technological traits. LWT 2017, 85, 445-448. [CrossRef]

11. Patanè, C.; Malvuccio, A.; Saita, A.; Rizzarelli, P.; Siracusa, L.; Rizzo, V.; Muratore, G. Nutritional changes during storage in fresh-cut long storage tomato as affected by biocompostable polylactide and cellulose based packaging. LWT 2019, 101, 618-624. [CrossRef]

12. Siracusa, L.; Patanè, C.; Rizzo, V.; Cosentino, S.L.; Ruberto, G. Targeted secondary metabolic and physico-chemical traits analysis to assess genetic variability within a germplasm collection of "long storage" tomatoes. Food Chem. 2018, 244, 275-283. [CrossRef] [PubMed]

13. Patanè, C.; Scordia, D.; Testa, G.; Cosentino, S.L. Physiological screening for drought tolerance in Mediterranean long-storage tomato. Plant Sci. 2016, 249, 25-34. [CrossRef] [PubMed]

14. Conesa, M.A.; Fullana-Pericàs, M.; Granell, A.; Galmés, J. Mediterranean long shelf-life landraces: An untapped genetic resource for tomato improvement. Front. Plant Sci. 2020, 10, 1651. [CrossRef] [PubMed]

15. Xu, Z.; Zhou, G.; Shimizu, H. Plant responses to drought and rewatering. Plant Signal. Behav. 2010, 5, 649-654. [CrossRef] [PubMed]

16. Patanè, C.; Tringali, S.; Sortino, O. Effects of deficit irrigation on biomass, yield, water productivity and fruit quality of processing tomato under semi-arid Mediterranean climate conditions. Sci. Hortic. 2011, 129, 590-596. [CrossRef]

17. Patanè, C.; Saita, A. Biomass, fruit yield, water productivity and quality response of processing tomato to plant density and deficit irrigation under a semi-arid Mediterranean climate. Crop Pasture Sci. 2015, 66, 224-234. [CrossRef]

18. Sharma, S.K.; Le Maguer, M. Kinetics of lycopene degradation in tomato pulp solids under different processing and storage conditions. Food Res. Int. 1996, 29, 309-315. [CrossRef]

19. Guida, G.; Houssemeddine Sellami, M.H.; Mistretta, C.; Oliva, M.; Buonomo, R.; De Mascellis, R.; Patanè, C.; Rouphael, Y.; Albrizio, R.; Giorio, P. Agronomical, physiological and fruit quality responses of two Italian long-storage tomato landraces under rain-fed and full irrigation conditions. Agric. Water Manag. 2017, 180, 126-135. [CrossRef]

20. Siracusa, L.; Avola, G.; Patanè, C.; Riggi, E.; Ruberto, G. Re-evaluation of traditional Mediterranean foods. The local landraces of 'Cipolla di Giarratana' (Allium cepa L.) and long-storage tomato (Lycopersicon esculentum L.): Quality traits and polyphenol content. J. Sci. Food Agric. 2013, 93, 3512-3519. [CrossRef]

21. Favati, A.; Lovelli, S.; Galgano, F.; Miccolis, V.; Di Tommaso, T.; Candido, V. Processing tomato quality as affected by irrigation scheduling. Sci. Hortic. 2009, 122, 562-571. [CrossRef]

22. Zhang, F.; Guo, J.K.; Yang, Y.L.; He, W.L.; Zhang, L.X. Changes in the pattern of antioxidant enzymes in wheat exposed to water deficit and rewatering. Acta Physiol. Plant. 2004, 26, 345-352. [CrossRef]

23. Upadhyaya, H.; Panda, S.K.; Dutta, B.K. Variation of physiological and antioxidative responses in tea cultivars subjected to elevated water stress followed by rehydration recovery. Acta Physiol. Plant. 2008, 30, 457-468. [CrossRef]

24. Maia Júnior, S.O.; Andrade, J.R.; Santos, C.M.; Silva, A.L.J.; Endres, L.; Silva, J.V.; Silva, L.K.S. Osmoregulators' accumulation minimizes the effects of drought stress in sugarcane and contributes to the recovery of photochemical efficiency in photosystem II after rewatering. Acta Physiol. Plant. 2020, 42, 62. [CrossRef]

25. Torrecillas, S.; Guillaume, C.; Alarcón, J.J.; Ruiz-Sánchez, M.C. 1995: Water relations of two tomato species under water stress and recovery. Plant Sci. 1995, 105, 169-176. [CrossRef]

26. Giorio, P.; Guida, G.; Mistretta, C.; Sellami, M.H.; Oliva, M.; Punzo, P.; Iovieno, P.; Arena, C.; De Maio, A.; Grillo., S.; et al. Physiological, biochemical and molecular responses to water stress and rehydration in Mediterranean adapted tomato landraces. Plant Biol. 2018, 20, 995-1004. [CrossRef]

27. Marín, A.; Rubio, J.S.; Martínez, V.; Gil, M.I. Antioxidant compounds in green and red peppers as affected by irrigation frequency, salinity and nutrient solution composition. J. Agric. Food Chem. 2009, 89, 1352-1359. [CrossRef]

28. Sarker, U.; Oba, S. Drought stress enhances nutritional and bioactive compounds, phenolic acids and antioxidant capacity of Amaranthus leafy vegetable. Plant Biol. 2018, 18, 258. [CrossRef]

29. Koyama, R.; Itoh, H.; Kimura, S.; Morioka, A.; Uno, Y. Augmentation of antioxidant constituents by drought stress to roots in leafy vegetables. HortTechnology 2012, 22, 121-125. [CrossRef]

30. Nangare, D.D.; Singh, Y.; Kumar, P.S.; Minhas, P.S. Growth, fruit yield and quality of tomato (Lycopersicon esculentum Mill.) as affected by deficit irrigation regulated on phenological basis. Agric. Water Manag. 2016, 171, 73-79. [CrossRef]

31. Slimestad, R.; Verheul, M. Review of flavonoids and other phenolics from fruits of different tomato (Lycopersicon esculentum Mill.) cultivars. J. Sci. Food Agric. 2009, 89, 1255-1270. [CrossRef]

32. Šamec, D.; Karalija, E.; Šola, I.; Vujčić Bok, V.; Salopek-Sondi, B. The role of polyphenols in abiotic stress response: The influence of molecular structure. Plants 2021, 10, 118. [CrossRef] 
33. Riggi, E.; Patanè, C.; Ruberto, G. Carotenoid content at different ripening stages in processing tomato in relation to soil water availability. Aust. J. Agric. Res. 2008, 59, 348-353. [CrossRef]

34. Balestrini, R.; Brunetti, C.; Cammareri, M.; Caretto, S.; Cavallaro, V.; Cominelli, E.; De Palma, M.; Docimo, T.; Giovinazzo, G.; Grandillo, S.; et al. Strategies to modulate specialized metabolism in Mediterranean crops: From molecular aspects to field. Int. J. Mol. Sci. 2021, 22, 2887. [CrossRef] [PubMed] 